\title{
An Investigation of Factors Influencing an Organisation's Intention to Adopt Cloud Computing
}

\author{
Nouf Alkhater \\ School of Electronics and Computer Science \\ University of Southampton \\ Southampton, United Kingdom \\ nrma1c12@ecs.soton.ac.uk
}

\author{
Robert Walters \\ School of Electronics and Computer Science \\ University of Southampton \\ Southampton, United Kingdom \\ rjw1@ecs.soton.ac.uk
}

\author{
Gary Wills \\ School of Electronics and Computer Science \\ University of Southampton \\ Southampton, United Kingdom \\ gbw@ecs.soton.ac.uk
}

\begin{abstract}
Cloud computing is a paradigm for providing and delivering IT services over the Internet. The cloud can provide several benefits for organisations including cost reduction and flexibility. However, migrating an existing system to the cloud is not an easy task because it is dependent on a number of factors. Therefore, this research aims to investigate the factors that may influence an organisation's intention to adopt cloud computing in Saudi Arabia. We proposed an integrated model in an attempt to understand why some organisations are willing to move to the cloud while others are not. This model incorporates aspects of the Technology-Organisation-Environment (TOE) framework with integrating the critical factors from existing theories (Diffusion of Innovations (DOI) and institutional theory) and other influential factors.
\end{abstract}

Keywords-cloud computing; adoption; technology-organisation -environment

\section{INTRODUCTION}

Cloud computing is a term used to describe distributed computing connected over a network to provide utility services to the end user [1]. The cloud allows users to access the service anytime and anywhere, and to only pay for what they use. Cloud computing was a dream in the sixties [2], when John McCarthy predicted the power of computing to provide utility services. In order to achieve this goal, a number of paradigms have been developed such as grid computing, but none succeeded in offering a public service the way cloud computing has.

Cloud computing offers several benefits for enterprises. The cloud frees organisations from having to set up an IT infrastructure and allows them to rent resources and pay only for the services they use [1]. This can reduce costs and save a lot of money for both small and large enterprises. In addition, cloud computing increases flexibility and offers an attractive opportunity for enterprises to grow [3]. However, some organisations still concerns about the idea of shifting a present system to the cloud.

A number of researchers in the past have made several attempts to help decision makers in the organisation to address their concerns about cloud adoption . It is noticeable that most of these proposed frameworks and models are focused on identifying the costs and benefits of adopting cloud computing and only a few empirical studies examine the influential factors on the adoption decision at an organisational level such as [4],[5].
Furthermore, the adoption rate of cloud computing is still in the early stages in Saudi Arabia. Therefore, this study aims to investigate these influential factors in depth and understand why organisations are willing to move to the cloud or why not. This research proposed an integrated model in an attempt to find out what might encourage an organisation to use cloud services or might impede them from using it.

\section{THE PROPOSED MODEL}

An integrated model has been developed to examine the most important factors that affect an organisation's decision to adopt the cloud. This model incorporates aspects of the Technology-Organisation-Environment (TOE) framework [6], also integrating the critical factors from Diffusion of Innovations (DOI) theory [7] and institutional theory [8] along with other factors (trust, privacy and physical location) that have not yet been studied but that may influence an organisation's decision to adopt the cloud. The research model consists of three fundamental factors: technological, organisational, and environmental factors. These are illustrated in the cloud computing adoption model (Fig. 1).

\section{A. Technological Factor}

The technological factor describes the characteristics of the cloud technology and identifies the factors that affect an organisation's decision to adopt this technology.

- Availability: Cloud computing offers resources online, meaning that the consumer can access the cloud from anywhere and at any time. This means the system needs to function properly and must be available to use whenever it is requested.

- Reliability: Refers to the ability of a system to fulfil its intended function in a proper manner as expected. It involves ensuring a high quality of service to end users, with a high transmission rate, minimum rate of errors, and fast recovery.

- Security: Refers to the level of security procedures in place to protect information or the system from unauthorised access or any other security events. Lack of security is one of the biggest doubts for many organisations that intend to adopt the cloud [9].

- Privacy: Defined as confidentiality of data, where only authorised users can access it. It is the main concern for organisations thinking about cloud computing because when using a cloud service an organisation cannot fully control the information stored on cloud-based servers. 
- Trust: Trust in the cloud environment heavily depends on trusting the service itself and the provider to provide a trusted level of authenticity, integrity and confidentiality in regard to the service and the stored data.

- Relative advantage: Relative advantage is an element of the DOI model [7]. This factor refers to the level of benefit to an organisation if they decide to move into cloud computing.

- Compatibility: Refers to the ability of the existing application to be compatible with the cloud. The compatibility of a firm's applications with the cloud environment is a real problem that an organisation needs to consider carefully when considering use of the cloud.

- Complexity: An organisation normally considers the degree of difficulty involved in using new technology as an important element in their decision before adopting this technology. This factor is also an element of the DOI model.

\section{B. Organisational Factor}

The organisational factor describes the characteristics of an organisation that might have a significant impact on their decision

- $\quad$ Top management support: Top management play an important role and have a significant impact on the adoption rate of IT innovations at the organisational level. Support from top management is essential because they have the ability to make the change and execute acceptance of the cloud.

- Organisation size: The size of the organisation is another influential factor. It is defined by the number of employees, the amount of investment involved, the target market and annual revenue.

- Technology readiness: The technological readiness of organisations, meaning the degree of readiness of the IT infrastructure and the human resources in terms of cloud computing.

\section{Environmental Factor}

The environmental factor determines the environmental elements that might affect an organisation's intention to use cloud technology.

- Compliance with regulations: This is an influential factor that can make a firm reluctant to move into cloud computing. This concern comes from the fact that there are no governmental regulations or rules that can support the firm in the event of a data breach. The lack of IT standards is a real problem that might obstruct adoption decisions [3].

- Competitive pressure: Defined as the degree of pressure that an organisation faces from competitors.

- Trading partner pressure: This pressure comes from vendors or other partners who might adopt cloud computing. Consequently, this might encourage an organisation to adopt this technology.

- Physical location: The physical location is a critical factor that affects an organisation's decision to adopt cloud computing for several reasons. First there are no international policies or regulations for data protection in the cloud. Second is the fact that some cloud providers store data in another country without disclosing this to end users [10].

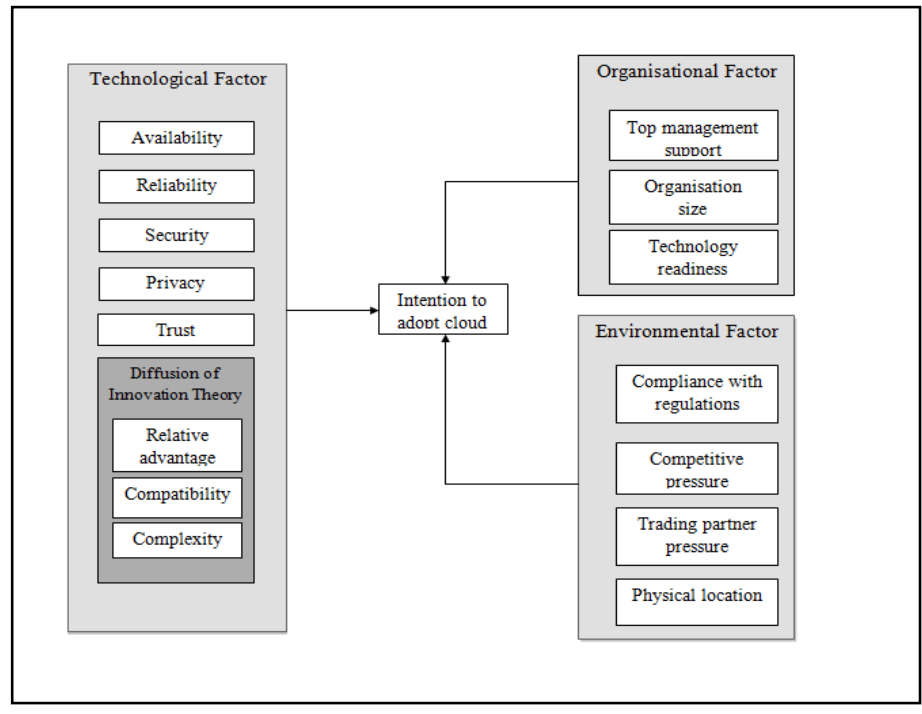

Figure 1 Cloud computing adoption model

\section{CONCLUSION}

Cloud computing is beneficial for companies and general users. However, moving a present system to the cloud is not an easy task because there are a number of factors that may affect an organisation's decision to move to the cloud. The purpose of this study is to investigate the factors that may influence an organisation's intention to adopt cloud computing. This is an ongoing research and future work will be focused on reviewing then validating the proposed model. The outcomes will be published soon.

\section{REFERENCES}

[1] R. Buyya, C. S. Yeo, S.Venugopal, J.Broberg, and I. Brandic, "Cloud computing and emerging IT platforms: vision, hype and reality for delivering computing as the $5^{\text {th }}$ utility," Future Gener.Comput. Syst.,vol. 25, pp. 599-616, 2009.

[2] X. Chen, G. Wills, L. Gilbert, and D. Bacigalupo,"Using cloud for research: a technical review," JISC Final Report, 2010.

[3] S. Marston, Z. Li, S. Bandyopadhyay, J. Zhang, and A.Ghalsasi, "Cloud computing - the business perspective,” Decis. Support Syst., vol. 51, no. 1,pp. 176-189, 2011. doi:10.1016/j.dss.2010.12.006

[4] C. Low, Y. Chen, and M. Wu, "Understanding the determinants of cloud computing adoption,” Ind. Manag. Data Syst., vol. 111, no. 7, pp. 10061023, 2011, doi:10.1108/02635571111161262.

[5] M. Nkhoma and D. Dang, "Contributing factors of cloud computing adoption: a technology-organisation-environment framework approach," Int. J. Inf. Syst. Eng., vol. 1, no. 1,pp. 38-49, 2013.

[6] L. G. Tornatzky and M. Fleischer, The Process of Technological Innovation. Lexington, MA: Lexington Books, 1990

[7] E. M. Rogers, Diffusion of Innovation, 4th ed. New York: Free Press, 1995.

[8] W. R. Scott, and S. Christensen, The Institutional Construction of Organizations: International and Longitudinal Studies. Thousand Oaks, CA: Sage, 1995

[9] A. Benlian and T. Hess, "Opportunities and risks of software-as-a-service: findings from a survey of IT executives,” Decis. Support Syst., vol. 52, no. 1,pp. 232-246, 2011.

[10] P. Jaeger, J. Lin, J. Grimes, and S. Simmons, "Where is the cloud? Geography, economics, environment, and jurisdiction in cloud computing," First Monday, vol. 14, no. 5, 2009. 